\title{
CCT Analysis and Effectiveness in e-Business Environment
}

\author{
Dr. Anasica S \\ MGM Department, The Free University of Berlin, Germany \\ anasica.s@ubingec.ac.in
}

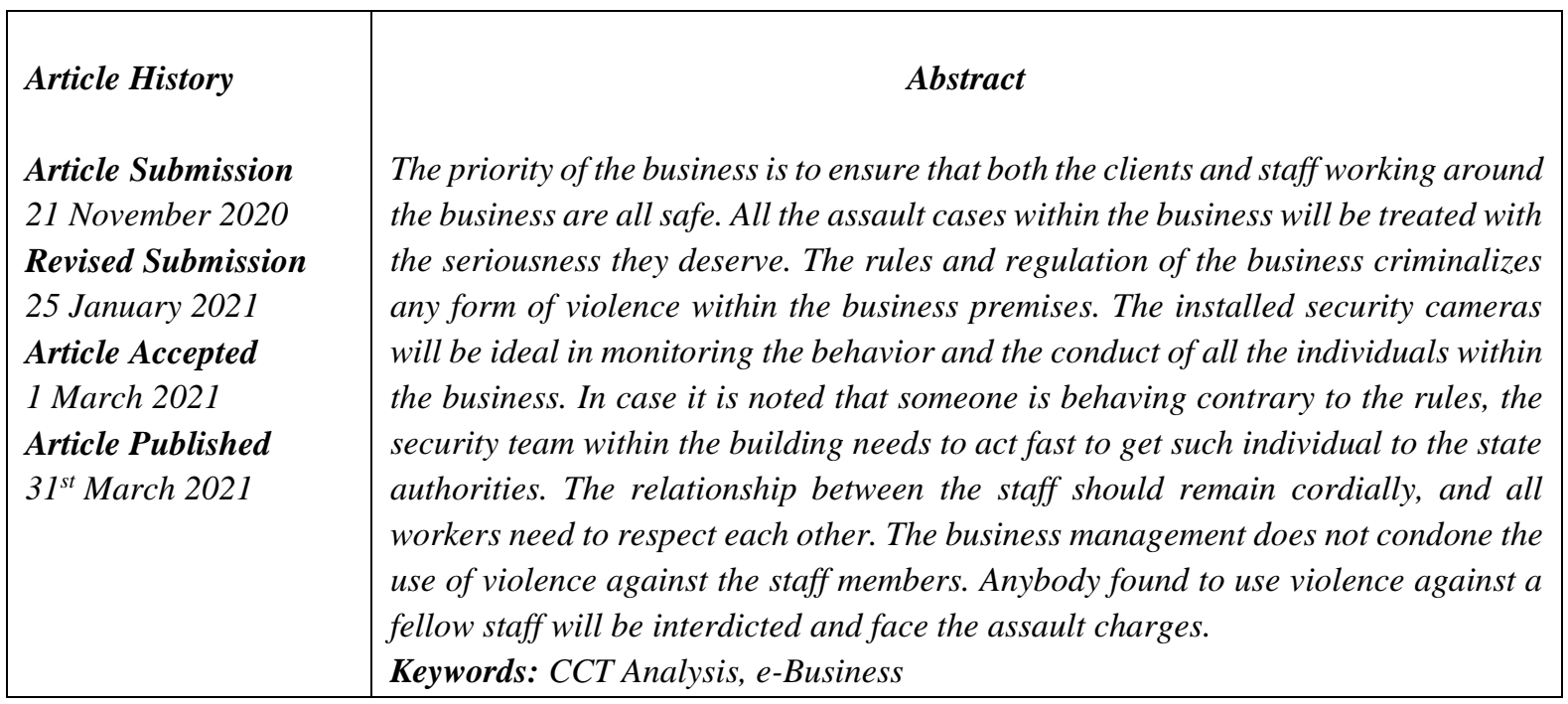

\section{Introduction}

In designing a new building, several factors have to be considered. However, security of the premise should be paramount in any construction. Therefore, buildings should be designed in a way that conforms to the safety of the users. This can only be ensure if the construction team comes up with a comprehensive plan that addresses the modern day security challenges (Demkin, 2004). The efforts to secure the building are not only limited to the contractors and construction consultants, but it extends to the people who will work in the facility once it is complete. For this reason, it is important that these people all learn the security solution that should be applied in securing the buildings. Most of the modern day buildings are designed in a way that it is difficult for the intruders to access them, without the knowledge of the staff. This paper explores an effective security plan that should be employed during and after the complete construction of a business.

\section{Methodology}

Given the increased insecurity, the business needs to be designed in a way that it is not possible for intrusions to take place. It is noted that the intruders, who later end up stealing properties in the business and sometimes attacking people who had visited the business, have attacked different libraries in the region. Therefore, a measure to address the possibility of such attacks should be implemented in the plan. This will keep at bay the burglars, who have malicious intention, once they enter the business. For this reason, the business will have the CCTV cameras. Several CCTV cameras will be mounted and linked to main operating area, where several security experts will be reviewing the images throughout the business's operation hours. Importantly, the entrance camera should have a designated security expert monitoring it always, especially after the working hours (American Institute of Architects, 2007). This is because it is still possible that the intruders will come, even after the business normal working hours have elapsed. The movements of all people entering the business will be captured in the camera. As a result, it becomes relatively easy for the intruders to be identified, given that they exhibit different 
behaviors around the business. In addition, the burglar alert system has to be installed, and it has to be frequently updated. This system is effective in monitoring the readers and visitors who have visited the business to ensure that they do end up leaving with a book without prior permission. It is noted that some people visit the business and end up coming out with books and other properties belonging the business (Fischer, Halibozek \&Walters, 2013; Walsh, 2009).

\section{Results and Discussion}

It is important that the business is kept safe from damages. The business's foundation should be strong making the structure firm from vandalism. The business has lot of valuables and therefore the security of these items is paramount. The interior of the business will be designed in a way it ensures there is free movement of people in accessing the business material. An effective way is through labeling all the books shelves for easier access, and prevent the damages to the material, as result of an intensive search (Demkin, 2004).

To prevent vandalism, only authorized persons will be allowed to the designed business. All the people entering the business have pass through the gate for automated security checks. When the security detects that someone has a strange materials, the gatekeeper has to stop them for further inspection to ascertain the materials they are carrying. In fact, if the person had the ill intentions, then the security officer should contact the police, for them to come and arrest the individual (American Institute of Architects, 2007).

To prevent theft of business books, no one will be allowed in the business, if they are carrying bags. As such, the entire luggage will be left in a special luggage store located to the left side of the business entrance. There shall be a security personality at the entrance to ensure that people with luggage are directed to the safe place, where the luggages are store for the time they will in the business. It is important to assure the clients that their luggage will be safe the entire period they will spend in the business (Fischer, Halibozek \&Walters, 2013).

The business should be organized in the sense that the access of reading space and books is easy. Whenever a client has a problem in locating books, it is important that the librarian is willing to ask them. Therefore, clients are asked to ask more information from the librarian, in order to prevent vandalizing properties within the business. Since the business does not serve for twenty hours, it is the librarian responsibility to ensure that the business is properly locked before leaving. Additionally, the night guard should be present at the business gate, in order to ensure that thieves do not break into the facility (Fischer, Halibozek \& Walters, 2013). It is the business management priority to ensure that personal property of the clients is safeguarded. The luggage store will be manned by a qualified security expert. The luggage has to be labeled according the owners identity, before they are kept in a compartment to avoid the chances of confusing with somebody's else. Therefore, the security officer the luggage officer has to be keen to ensure that procedure conforms to the rules stated by the management (Demkin, 2004).

Given that the system used in the business has to keep clients information confidential, it is important that information communication experts ensure the encryption of information. This will ensure that unauthorized access is prevented ad no chance is given to the malicious people that could alter the information. In doing this, all the business records will be have the correct details. Since the readers will be allowed to access the machines at the office, the security permissions for the machines used by the clients should be limited. They should not be able to alter the system design, but only use the 
computer system helping them access to the business material. Business members will be allocated with $\log$ in details, and only members with online accounts will be logged into the online resource business. However, the online resources will only be limited in cases where the books in the business are not enough, or they are lacking.

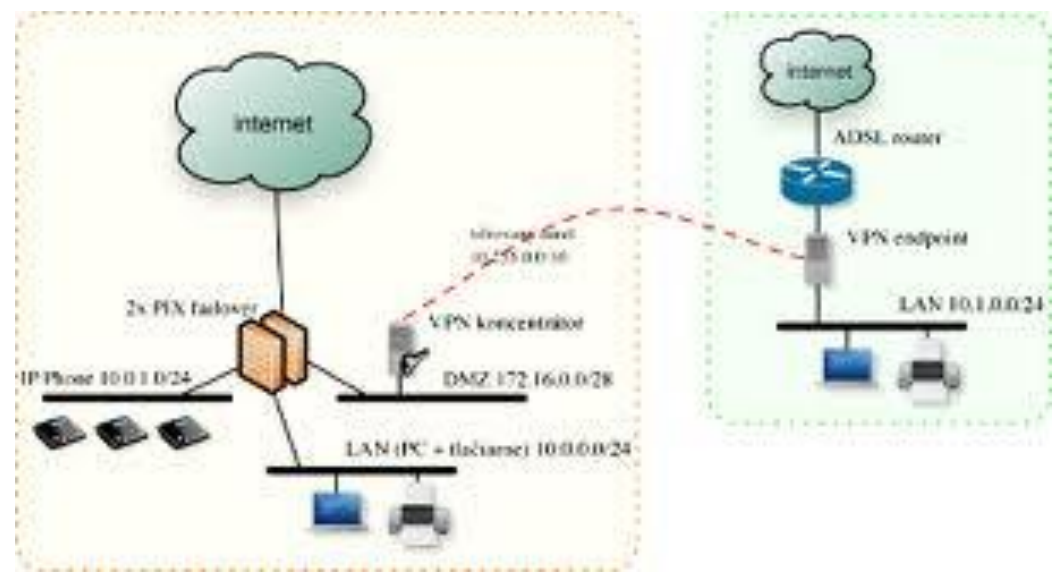

Figure 1: System Process Architecture

\section{Conclusion}

In conclusion, this paper has examined an effective security plan that should be employed during and after complete construction of the business. It has found that buildings should be designed in a way that conforms the safety of the users. This can only be ensure if the construction team comes up with a comprehensive plan that addresses the modern day security challenges. Given the increased insecurity, the business needs to be designed in a way that it is not possible for intrusions to take place. The priority of the business is to ensure that both the clients and staff working around the business are all safe. All the assault cases within the business will be treated with the seriousness they deserve. It is important that the business is kept safe from damages. The business has lot of valuables and therefore the security of these items is paramount. It is established that some legal issues may emerge between the contractor and the consultants. For this reason, there should be clear steps that would help in resolving the issues.

\section{References}

[1] American Institute of Architects. (2007). Architectural Graphic Standards. New Jersey. John Wiley \& Sons.

[2] Demkin, J. (2004). Security Planning and Design: A Guide for Architects and Building Design Professionals. New York: John Wiley \& Sons.

[3] Fischer, R. Halibozek, E. \& Walters, D. (2013). Introduction to Security (9th Ed.). Boston, MA: Butterworth-Heinemann.

[4] Ms. Nora Zilam Runera. (2014). Performance Analysis On Knowledge Management System on Project Management. International Journal of New Practices in Management and Engineering, 3(02), 08 - 13. Retrieved from http://ijnpme.org/index.php/IJNPME/article/view/28

[5] Walsh, D. (2009). Employment Law for Human Resource Practice. San Francisco: Cengage Learning. 